\title{
Институциональные стратегии внедрения цифровых ресурсов обратной связи с населением в регионах России
}

\author{
К. С. Кондратенко \\ Санкт-Петербургский государственный университет \\ kondratenkoks@inbox.ru
}

\section{Аннотация}

Статья посвящена стратегиям внедрения цифровых каналов публичной политики в регионах РФ. Проблема исследования заключается в неравномерности внедрения ресурсов обратной связи в различных регионах РФ, при этом внедрение указанных технологий описано в паспорте федерального проекта «Цифровое государственное управление». Основная гипотеза данной статьи заключается в том, что регионы выбирают различные стратегии внедрения каналов публичного участия, по-разному решая вопрос соотношения монополизма в данной сфере и возможностей рационального выбора при создании региональных сайтов. Какие стратегии внедрения лежат в основании институциональных матриц регионов РФ - основной вопрос данной статьи.

Ключевые слова: ресурс обратной связи, платформа, участие, регион, регион РФ, цифровизация, институт, институциональная стратегия, внедрение цифровых технологий.

Библиографическая ссылка: Кондратенко К.С. Институциональные стратегии внедрения цифровых ресурсов обратной связи с населением в регионах РФ // Государство и граждане в электронной среде. Выпуск 4 (Труды XXIII Международной объединенной научной конференции «Интернет и современное общество», IMS-2020, Санкт-Петербург, 17-20 июня 2020 г. Сборник научных статей). - СПб: Университет ИТМО, 2020. С. 46-58. DOI: 10.17586/2541-979X-4-46-58

\section{1. Введение}

Новые технологии, внедряемые и осваиваемые обществом, обладают серьезным потенциалом институциональной трансформации - с этим, казалось бы, сложно поспорить. Мысль, восходящая еще к К. Марксу, заключается в фундаментальном факторе производственных сил, влияющих не только на сферу производства и потребления, но и на общество в целом. Технологические уклады частично или полностью трансформируют мировую экономику, влияя и определяя длину экономических циклов, имеющих разные периоды: от 45 до 60 лет (Н.Д. Кондратьев) [1], от 15 до 25 лет (С. Кузнец) [2], от 7 до 11 лет (К. Жюгляр) [3], от 3 до 4 лет (Дж. Китчин) [4]. Надо полагать, современные цифровые инновации также обладают трансформационным потенциалом, однако до сих представляются затруднительными для решения проблемы, связанных с внедрением новых институтов и их взаимосвязей с системой сложившихся институтов.

Теория экономических циклов неплохо обосновывает актуальность исследования роли и методов внедрения инноваций. Долгосрочные циклы Н.Д. Кондратьева непосредственно влияют на среднесрочные и краткосрочные циклы: так, например, характер движения «национальных» циклов С. Кузнеца, зависящих от роста народонаселения и миграции, связан с технологическим укладом, равно как «инвестиционные» циклы, открытые К. Жюгляром, и циклы «временного лага», обоснованные Дж. Китчиным. Рост технологий 
или их старение, таким образом, более важен, чем инвестиции, время, затраченное на принятие решений, и даже рост народонаселения.

В данной статье исследуется такой сегмент цифровой трансформации, как ресурсы обратной связи с населением. Выбор данного аспекта не является случайным - новые цифровые технологии, такие, как использование больших данных, искусственного интеллекта и интернета вещей, т.н. сквозные технологии, сегодня в публичном секторе можно наблюдать, скорее, в рамках отдельных инициативных проектов, в свою очередь, цифровые каналы участия - скорее, складывающаяся тенденция и обретающая популярность технология. Также стоит подчеркнуть, что в данном исследовании понятия «сайты обратной связи», «ресурсы обратной связи» и «цифровые каналы участия» будут использоваться в качестве синонимов, поскольку под нередко употребляемым в данном контексте понятие «платформа» автор подразумевает не сайт или ресурс, а единую систему управления информацией. Такое разграничение сделано, в частности, в докладе правительства Б. Обамы от 23 мая 2012 г., в котором система публичных услуг разделена на три уровня: уровень информации, уровень платформы и уровень представления [5]. Сайты и мобильные приложения, таким образом, относятся к уровню представления, а не платформы. Такой подход в целом соответствует разграничению понятий «платформа» и «сервис», представленный в «Программе развития Цифровой (электронной) экономики в РФ до 2035 года», в которой под платформой понимается: 1. модель деятельности (в том числе бизнес-деятельности) заинтересованных лиц на общей платформе для функционирования на цифровых рынках; 2. площадка, поддерживающая комплекс автоматизированных процессов и модельное потребление цифровых продуктов (услуг) значительным количеством потребителей; 3. информационная система, ставшая одним из лидирующих решений в своей технологической нише (транзакционной, интеграционной и т.п.) [6]. Также в «Программе» дается разъяснение разделения государственной цифровой платформы и услуг и сервисов, к которым платформа предоставляет доступ [6]. Более подробный анализ понятия «цифровая платформа» содержится в статье В.И. Меденникова «Математическая модель формирования цифровых платформ управления экономикой страны» [7].

\section{2. Обзор литературы}

Ресурсы обратной связи с населением, базирующиеся на институтах активного взаимодействия, открытости и краудсорсинга, не относятся к разряду эпохальных или базисных инноваций. В терминологии Ю.В. Яковца, цифровые каналы участия - это микроинновации и инновации улучшающего типа [8], хотя в целом относятся к фундаментальным факторам институциональной трансформации [9]. Движущая сила институциональной трансформации - институциональный рынок, прошедший «фильтр» политического рынка, по правилам которого приоритет отдается институтам с нулевыми транзакционными издержками. Существующая сегодня система взаимодействия граждан с органами государственной власти предполагает институциональное равенство между офлайн- и онлайн-взаимодействием, однако это не означает, что между ними отсутствует конкуренция. Устаревшие институты перестают отвечать ситуации, времени, ожиданиям; на смену старым институтам приходят новые, и в результате конфликта происходит обновление институтов, на что указывал еще Т. Веблен [10].

Исследование стратегий внедрения цифровых ресурсов обратной связи с населением это анализ институциональных правил ведения политического торга. Такая точка зрения несколько охлаждает исследовательский пыл в рассмотрении конструктивных функций инноваций, внедряемых государством, на что указывали Р.Д. Аткинсон, С.Дж. Эцелль, Д. Брезнитц, Д. Норт и др. Р.Д. Аткинсон и С.Дж. Эцелль описывают важность государства при формировании экономики инноваций, при этом авторы подчеркивают сложность этой цели: государству следует быть не монополистом, контролирующим весь 
процесс, а гибким стимулирующим агентом, с одной стороны, создающим возможности для технологического прорыва, с другой - умеющим перераспределить функции управления сегментами инновационной экономики в частные руки [11]. Д. Брезниц, в свою очередь, указывает на невозможность инновационного прорыва отсталой экономики к высокотехнологичной экономике инноваций, используя только политические возможности [12]. Д. Норт более категоричен в своих суждениях: «Политическим системам органически присуща тенденция производить на свет неэффективные права собственности, которые приводят к стагнации и упадку» [13]. Проблема неэффективности государственного участия выражается, в частности, в самом механизме государственных закупок: фирма, выполняя заказ, ориентируется, в первую очередь, не на потребителя, а на заказчика. Чтобы уравновесить этот дисбаланс, регионы пытаются обойти данную проблему, перенимая успешно зарекомендовавшие себя практики в других регионах, в частности, обращаясь к фирме-производителю, имеющей опыт создания сайтов для региональных правительств и администраций (так, например, белгородская компания «Infolabs» выполнила не только заказ Правительства Белгородской области - сайт «Народная экспертиза» [14], но также заказы Брянской, Курской, Свердловской области и Приморского края).

Подобные проекты, несмотря на затраты, связанные с созданием и поддержкой сайтов, а также обучением сотрудников и привлечением активных граждан, представляют собой в перспективе выгодное вложение с точки зрения сокращения транзакционных издержек, однако здесь также есть две стороны: удобство, доступность информации и относительно малозатратный способ обращения в органы государственной власти с целью привлечения внимания к той или иной проблеме, голосования, жалобы и пр. представляется выгодным для всех сторон контракта. Однако эта же самая легкость и доступность в перспективе может привести к стремительному росту обращений в ОГВ, что приведет к фактической невозможности удовлетворения потребностей всех граждан и последующему разочарованию. Резкое увеличение числа активных пользователей может привести к такому же резкому спаду и по другой причине, связанной с неравновесностью потока проблем и потока информации. Проблем намного меньше, чем сообщений об этих проблемах. Если сравнить количество сообщений десяти наиболее активных пользователей портала «Наш Санкт-Петербург» с количеством решенных проблем, указанных в сообщениях, то получится, что решенных проблем примерно в три раза меньше, чем сообщений о проблемах [15]. Если же неравенство увеличится, скажем, в десять раз, то пользователь может сделать вывод о том, что рядом с ним живут более успешные и активные пользователи, быстрее реагирующие на проблемы, а отклик государства на каждую десятую указанную проблему окажется причиной низкой самоэффективности пользователей. В итоге это может привести к замене открытых каналов участия для граждан на закрытые обсуждения «кураторов районов» и дальнейшей институционализации (или сосуществованию форматов «для всех» и «для активных граждан»).

Уменьшение описанных выше рисков возможно благодаря выбору наиболее перспективной траектории институциональной трансформации. Логика институциональной трансформации, согласно О.Е. Уильямсону, движется с нижнего уровня, концентрирующего максимум усилий, к верхнему (табл. 1).

Таблица 1. Классификация институтов, согласно О.Е. Уильямсону [17]

\begin{tabular}{|l|l|}
\hline \multicolumn{1}{|c|}{ Институциональные уровни } & \multicolumn{1}{|c|}{ Частота трансформации } \\
\hline неформальные институты & $100-1000$ лет \\
формальные институты & $10-100$ лет \\
институты управления & $1-10$ лет \\
правила, прописанные в контрактах & постоянно \\
\hline
\end{tabular}


Уровень правил распределения ресурсов формирует большую часть стратегии институциональной трансформации, это тактический уровень программ развития, в то время как уровень транзакций и структур управления составляет стратегическое ядро, определяя характер и специфику стратегии в целом. Тактический уровень достаточно подробно описан В.М. Полтеровичем в работе «Стратегии институциональных реформ. Перспективные траектории» [16].

Выбор перспективной институциональной траектории, согласно В.М. Полтеровичу, зависит от таких институциональных условий, как выбор институционального пространства, ресурсные ограничения, технологические ограничения, особенности гражданской культуры и человеческий капитал, политические ограничения - принятие решений о проведении реформ, комплементарность институтов и последовательность реформ, ослабление ограничений вдоль траектории, сдерживание перераспределительной активности, формирование благоприятных институциональных ожиданий и стимулирование движения вдоль траектории, Парето-улучшение и компенсация потерь [16]. Большая часть условий относится именно к возможности адекватной стратегии распределения ресурсов. Собственно, выбор перспективной траектории возможен, согласно работе вышеупомянутого исследователя, из трех вариантов: «шоковой терапии», выращивания институтов и промежуточных институтов, последняя при этом - наиболее удачная. Ту же мысль озвучивают Е.М. Стырин, Н.Е. Дмитриева и Л.Х. Синятуллина, полагая, что «издержки и риски масштабного внедрения цифровых технологий могут превысить ожидаемые выгоды. Поэтому, чтобы избежать рисков, в том числе в области кибербезопасности и защиты персональных данных граждан, наиболее приемлемым представляется инкрементальный подход к внедрению цифровых инноваций» [18]. При этом отправной точкой внедрения инноваций является трансплантация институтов, успешно зарекомендовавших себя в других странах и регионах [19].

Внедрение цифровых каналов участия может пройти достаточно быстрыми темпами, поскольку граждане в целом считают получение государственных услуг в электронном виде более удобным и эффективным (так, например, в 2019 году Россия заняла третье место по темпам роста использования госуслуг в электронном виде) [20]. Надо полагать, что сложились неплохие условия для выбора граждан перспективы эффективности, хотя иные стратегии также могут иметь место, в частности, перспектива моды (об этом, в частности, свидетельствует внедрение сайтов для онлайн-голосований «Активный гражданин» в Нальчике, Калуге, Липецке, Уфе, Тюмени и других городах и регионах). Не исключено, что в отдельных регионах призыв региональных администраций использовать сервисы обратной связи с населением может восприниматься отдельными акторами как причуда руководства или принуждение [21]. Региональные администрации при этом привлекают активных пользователей в основном посредством геймификации, что выглядит довольно слабой технологией по сравнению с денежными призами, подарочными сертификатами, благодарностями и пр. [22].

Наконец, стоит также отметить важность при реализации стратегии внедрения цифровых каналов участия следования базовым правилам, к которым относятся:

- открытость, прозрачность и инклюзивность;

- участие в разработке политики и предоставлении услуг;

- создание управляемой данными культуры в государственном секторе;

- защита конфиденциальности и обеспечение безопасности;

- лидерство и политическая приверженность;

- согласованное использование цифровых технологий во всех областях политики;

- эффективные организационные и управленческие структуры для координации;

- укрепление международного сотрудничества с правительствами;

- разработка понятных бизнес-кейсов;

- усиление возможности управления проектами ИКТ;

- закупка цифровых технологий; 
- нормативно-правовая база [23].

Схожие принципы обозначены в задачах подпрограммы «Информационное государство» государственной программы «Информационное общество», такие, как развитие механизмов предоставления гражданам и организациям государственных (муниципальных) услуг (реализации функций), иных услуг (сервисов) и сведений с использованием современных информационно-телекоммуникационных технологий; повышение открытости, эффективности и качества функционирования механизмов электронного взаимодействия органов государственной власти и органов местного самоуправления, физических и юридических лиц; повышение надежности и защиты государственных информационных систем и сервисов; повышение удобства использования гражданами, организациями и органами государственной власти и органами местного самоуправления государственных (муниципальных) информационных систем и сервисов; сохранение ретроспективной архивной информации и перевод ее в электронный вид для эффективного использования в интересах государства, общества и граждан; реализация комплексных проектов на территории Российской Федерации в целях развития информационно-телекоммуникационных технологий; создание национальной системы управления данными; развитие и применение перспективных «сквозных» цифровых технологий в области цифровой экономики [24]. Также в государственной программе «Информационное общество» указано, что один из результатов программы, заключающийся в вовлеченности граждан и организаций в процессы государственного управления посредством обеспечения возможности электронного взаимодействия с органами государственной (муниципальной) власти в рамках исполнения государственных (муниципальных) функций, в том числе создание новых механизмов такого взаимодействия, планируется достигнуть к 31 декабря 2022 г. (какие именно механизмы взаимодействия между государством и гражданами должны быть созданы - не уточняется). Однако регионы могут воспользоваться тем, что другим мероприятием подпрограммы «Информационное государство» является поддержка региональных проектов в сфере информационных технологий, срок реализации которого истекает 31 декабря 2024 г. (такие сроки реализации связаны с продлением в апреле 2019 г. государственной программы «Информационное общество» до 2024 г. [25]. Также существенно увеличено финансирование программы: так с 2011 по 2018 гг. средний объем финансирования составлял 123,7 млрд. руб., а с 2019 по 2024 гг. - 270,5 млрд. руб. [26]. Увеличение финансирования связано с интеграцией нацпрограммы «Цифровая экономика» в госпрограмму «Информационное общество») [27].

Создание цифровых каналов участия соответствует также целям, обозначенным в федеральном проекте «Цифровое государственное управление», а именно обеспечение предоставления государственных и негосударственных услуг и сервисов в цифровом виде в соответствии с прогрессирующими потребностями современного общества в условиях становления цифровой экономики; обеспечение цифровой трансформации органов государственной власти и органов местного самоуправления, направленной на повышение качества осуществления возложенных на них функций, уменьшение издержек при их осуществлении, создание системы управления данными, в том числе сбора, хранения, обработки и распространения данных; обеспечение эксплуатации и развития инфраструктуры электронного правительства [28]. Таким образом, внедрение цифровых ресурсов обратной связи с населением подчинено институциональной трансформации и обретает в настоящий момент формальные правила и принципы.

\section{3. Методика исследования и источники данных}

Данное исследование направлено на анализ стратегии внедрения цифровых ресурсов обратной связи с населением в федеральных округах РФ. Для этого использовался корреляционный анализ данных, а также анализ частот. При этом статистические методы 
применялись как по округам, так и по всем субъектам РФ. Основными теоретикометодологическими аспектами исследования выступают наличие/отсутствие статистически значимых связей между переменными и степень исполнительности региональной бюрократии. При этом наличие статистической значимости между переменными должно указывать на способ управления и соответствующую стратегию: ориентацию на нужды и потребности граждан (good governance), ориентацию на бюджет и затраты (new public management) и/или ориентацию на новые технологии и алгоритмизацию публичного управления (good algorithmic governance). Охват субъектов РФ, в свою очередь, укажет на уровень реализации государственной программы РФ «Информационное общество».

Чтобы достичь основную цель исследования, а именно дать характеристику региональным стратегиям внедрения цифровых каналов участия, было исследовано наличие/отсутствие соответствующих ресурсов. Далее, для детализации исследования, были отобраны переменные, наиболее точно отражающие описанные выше стили управления, а именно:

- население, взаимодействующее с органами государственной власти и местного самоуправления через сеть Интернет (используя официальные сайты и порталы государственных и муниципальных услуг, мобильные устройства, электронную почту и терминалы самообслуживания), 2018 г. [29];

суммарные ИКТ-расходы на душу населения в 2018 г., Р [30];

- результаты аудита открытости сайтов высших исполнительных органов государственной власти субъектов РФ, 2018 г. [31];

наличие/отсутствие цифровых каналов участия в регионе (имеются в виду не электронные приемные региональных администраций, правительств республик или губернаторов, а специализированные сайты-агрегаторы жалоб, обращений, голосований и пр.) [32].

Указанные данные взяты за 2018 г., тогда как наличие/отсутствие цифровых каналов участия - за 2020 г., поскольку имплементация стратегии требует определенного времени.

\section{4. Результаты}

На первом этапе исследования была проанализирована нормальность распределения данных при помощи одновыборочного t-критерия Стьюдента. Результаты исследования представлены ниже (табл. 2).

Таблица 2. Результаты анализа нормальности распределения значений

\begin{tabular}{|l|l|c|c|c|}
\hline № & \multicolumn{1}{|c|}{ Переменные } & Ср. знач. & t-критерий & р-значимость \\
\hline 1. & Интернет-пользователи & 48,459 & 27,813 & 0,000 \\
2. & ИКТ-расходы & 608,285 & 4,773 & 0,000 \\
3. & Открытость & 40,149 & 12,746 & 0,000 \\
4. & Цифровой канал участия & 0,58 & 10,693 & 0,000 \\
\hline
\end{tabular}

Данные показывают, что большая часть переменных вращается вокруг средних величин - среднее количество пользователей, обратившихся в ОГВ посредством сети Интернет, составляет 48,5\%, открытость официальных сайтов региональных администраций $-40,1 \%$, а цифровые ресурсы обратной связи с населением внедрены в $58 \%$ субъектов РФ. Все выбранные переменные являются статистически значимыми, однако у двух критериев фиксируется недопустимое превышение нормальности распределения - количество интернет-пользователей и результаты аудита открытости сайтов высших ИОГВ субъектов РФ (наличие/отсутствие цифрового канала участия является бинарной переменной, поэтому оценкой нормальности распределения в данном 
случае можно пренебречь), что свидетельствует о сомнительности методологии анализа статистических данных, представленных в указанных источниках. Тем не менее, pзначимость каждой переменной стремится к нулю, поэтому эти переменные могут быть использованы в корреляционном анализе.

Корреляционный анализ переменных выявил только одну статистически значимую связь между переменными «результаты аудита открытости сайтов высших ИОГВ субъектов РФ» и «наличие/отсутствие цифровых каналов участия в регионе» $(\mathrm{r}=0,217$; $\mathrm{N}=85 ; \mathrm{p}=0,046$ ), что свидетельствует о слабой тенденции субъектов РФ к стратегии внедрения цифровых каналов участия, ориентированных на технологии и алгоритмизацию управления. Чем выше показатель открытости и содержания официальных сайтов региональных администраций, тем выше вероятность наличия новых цифровых сервисов, предназначенных для взаимодействия граждан и государства.

Анализ был проведен также по федеральным округам РФ и выявил довольно сильную взаимосвязь показателей «население, взаимодействующее с органами государственной власти и местного самоуправления через сеть Интернет» и «наличие/отсутствие цифровых каналов участия в регионе» в Центральном ФО (r=0,492; $\mathrm{N}=18 ; \mathrm{p}=0,038)$.

Это говорит о технократических тенденциях внедрения цифровых каналов участия и ориентацию на потребности самих пользователей: чем выше количество граждан, обращавшихся о ОГВ посредством сети Интернет, тем выше вероятность наличия цифровых ресурсов обратной связи с населением, что свидетельствует о характере принятия решений в ЦФО - перед принятием решения о создании цифрового сервиса в том или ином субъекте ЦФО губернаторы и региональные департаменты ориентируются на статистику и, вероятно, на нужды и потребности самих граждан.

Других статистически значимых взаимосвязей корреляционный анализ не выявил. Тем не менее, частотный анализ послужил основанием для выводов об уровне реализации отдельных положений подпрограммы «Информационное государство» государственной программы «Информационное общество». Частотные характеристики представлены далее (табл. 3).

Таблица 3. Распределение субъектов РФ, внедривших сервисы обратной связи с населением, по федеральным округам

\begin{tabular}{|l|c|}
\hline \multicolumn{1}{|c|}{ Федеральный округ } & $\begin{array}{c}\text { Количество субъектов РФ, } \\
\text { внедривших цифровые } \\
\text { сервисы обратной связи, \% }\end{array}$ \\
\hline Дальневосточный & 72,7 \\
Приволжский & 42.9 \\
Северо-Западный & 72,7 \\
Северо-Кавказский & 42.9 \\
Сибирский & 50,0 \\
Уральский & 83,3 \\
Центральный & 55,6 \\
Южный & 50,0 \\
\hline
\end{tabular}

Средний показатель по федеральным округам - 58,8\%, что свидетельствует о среднем уровне реализации отдельных положений подпрограммы «Информационное государство» в целом по стране. Это неплохой показатель, учитывая, что ближайший отчетный период закончится 31 декабря 2022 г. Если взять за основу классификации высокий, средний и низкий уровни реализации, то значения будут расположены по шкале $0-100 \%$ на отметках $33,3 \%$ и $66,6 \%$ соответственно. Из этого следует, что три федеральных округа Дальневосточный, Северо-Западный и Уральский наиболее активно участвуют в реализации указанных мероприятий программы «Информационное общество», степень реализации можно оценить как высокую, в то время как пять остальных федеральных 
округов - Приволжский, Северо-Кавказский, Сибирский, Центральный и Южный - в меньшей степени прикладывают усилия для реализации программы, уровень которых можно оценить как средний.

Описанные результаты исследования указывают на два ключевых аспекта: внедрение цифровых технологий в регионах РФ говорит о формирующейся системе «алгоритмического управления», о начальной стадии этого процесса - управления алгоритмов (governance of algorithms), что впоследствии может привести к управлению посредством алгоритмов (governance by algorithms). Забота о качестве и объеме информации, представленной на сайтах администрации, будь то отчеты, планы, мероприятия, порядок участия граждан и пр., вероятно, сказывается на стремлении регионов упорядочивать, алгоритмизировать процессы управления, в том числе, посредством цифровых каналов участия. С другой стороны, иной стратегии, помимо официально опубликованных и принятых стратегий развития, государственных программ и национальных проектов, в регионах не сформировано. Уникальных путей регионов в сторону развития «умного управления» на данный момент не существует. Если центр управления не налагает санкции за слабую степень реализации государственных программ, то это предоставляет возможность регионам не спешить с реализацией ненужных им проектов. Отсюда следует достаточно пессимистический вывод о тождестве особенностей стратегии внедрения цифровых ресурсов взаимодействия с населением и специфики федерального управления этим процессом.

\section{5. Обсуждение}

Цифровизация публичной власти в России представляет собой любопытный феномен. Несмотря на то, что в исследовании было выявлено отсутствие региональных стратегий внедрения цифровых сервисов, стоит отметить при этом, что сами проекты выглядят очень достойно, соответствуя не только российским ГОСТам, но и международным стандартам качества. Талантливые разработчики, такие, как «Infolabs», «Metropolis Studio», «WhiteSoft», «B1Team» и др. совместно с региональными департаментами цифрового развития смогли представить качественный и удобный продукт, полезный для населения и удобный в использовании. Отсюда следует, что заслуги в сфере цифровизации экономики и публичной власти не принадлежат только лишь Министерству цифрового развития, связи и массовых коммуникаций Российской Федерации, а также подведомственных ему департаментах, органах и организациях, но также и частным компаниям, успешно зарекомендовавшим себя на рынке. Однако феномен цифрового публичного управления заключается не только и не столько в отлаженной работе сетевых акторов. Суть парадокса цифровизации заключается в том, что, согласно мировым рейтингам, Россия является если не лидером в сфере электронного правительства, электронного участия и пр., то, по крайней мере, занимает довольно высокие позиции в рейтинге. Так, например, в 2020 году РФ заняла 36 место по Индексу развития электронного правительства и 27 место в мире по Индексу электронного участия, что следует из отчета ООН [33]. В то же самое время качество государственного управления в РФ оставляет желать лучшего: в 2018 году Всемирный банк оценил свободу слова и степень защиты избирательных прав россиян на уровне 19,2\%, эффективность государственного управления - 51\%, умение правительства осуществлять разумную политику, способствующую развитию частного сектора, $-31,7 \%$, качество работы правоохранительных органов - 20,7\% [34].

Правдоподобным объяснением этого «парадокса цифровизации» может выступить упомянутое в работе разделение формальных и неформальных институтов: по всей видимости, чем больше неформальные институты доминируют над формальными, тем меньше их эффективность (впрочем, это вопрос отдельного исследования). Неформальные институты цифровой экономики на данный момент находятся в процессе формирования. Правительство РФ, с одной стороны, активно стимулирует стартапы и инициативные 
проекты в данной сфере, но, с другой, проявляет себя как монополист, навязывая регионам «правила игры»: методические рекомендации, стандарты и даже поставщиков (яркий пример - «Ростелеком»). При этом остается открытым вопрос о полезности цифровых каналов участия ввиду достаточно низкого относительно стран Евросоюза уровня доверия к органам государственной власти и большой дистанции между государством и обществом в России. Помимо этого, стоит отметить, что цифровые каналы участия явно далеки от пика своей популярности в качестве эффективного инструмента решения городских и местных проблем. Пик популярности этих ресурсов в ближайшей перспективе, надо полагать, не предвидится.

Работа выполнена при финансовой поддержке Российского научного фонда, грант № 19-18-00210 «Политическая онтология цифровизации: исследование институциональных оснований цифровых форматов государственной управляемости».

\section{Литература}

[1] Кондратьев Н.Д. Большие циклы коньюктуры и теория предвидения. Избранные труды. М.: «Экономика», 2002.

[2] Abramovitz M. The passing of the Kuznets cycle. Economica. New series. 1968ю Vol. 35, №140. P. 349-367.

[3] Juglar C. Des crises commerciales: et de leur retour periodique en France, en Angleterre et aux Etats-Unis / par Clement Juglar; ouvrage couronne par l'Institut (Academie des Sciences morales et politiques). Guillaumin et C-ie, Libraires-Editeurs, 1862.

[4] Kitchin J. Cycles and Trends in Economic Factors // The Review of Economics and Statistics. 1923. Vol. 5, №1. P. 10-16.

[5] Digital government: Building a 21st century platform to better serve the American people, May 23, $2012 . \quad$ URL: https:/obamawhitehouse.archives.gov/sites/default/files/omb/egov/digitalgovernment/digital-government-strategy.pdf (accessed: 01.01.2020).

[6] Программа развития Цифровой (электронной) экономики в РФ до 2035 года. URL: https://aetp.ru/news/item/410256 (дата обращения: 01.01.2020)

[7] Меденников В.И. Математическая модель формирования цифровых платформ управления экономикой страны // Цифровая экономика. 2019. № 1 (5). С. 25-35.

[8] Яковец Ю.В. Глобальные экономические трансформации XXI века. М.: Экономика; 2011. С. 46-47.

[9] Полтерович В.М. Институциональные ловушки и экономические реформы. М., 1998. C. 6 .

[10]Веблен Т. Теория праздного класса. М.: Изд-во «Прогресс», 1984. С. 200-202.

[11]Atkinson R.D., Ezell S.J. Innovation Economics. The Race for Global Advantage. Yale University Press, 2012. P. 133-161.

[12]Breznitz D. Innovation and the State. Political Choice and Strategies for Growth in Israel, Taiwan, and Ireland. Yale University Press, 2007.

[13]Норт Д. Институты, институциональные изменения и функционирование экономики. М.: Фонд экономической книги «Начала», 1997. С. 97.

[14]Проект «Народная экспертиза». URL: https://narod-expert.ru (дата обращения: 01.01.2020).

[15]Портал «Наш Санкт-Петербург». URL: https:/gorod.gov.spb.ru/ratings/users/ (дата обращения: 01.01.2020).

[16] Полтерович В.М. Стратегии институциональных реформ. Перспективные траектории // Экономика и математические методы. 2006. Т. 42, № 1. С. 3-18.

[17]Williamson O.E. The New Institutional Economics: Taking stock, Looking ahead // Journal of economic literature. 2000. Vol. 38. P. 595-613. 
[18]Стырин Е.М., Дмитриева Н.Е., Синятуллина Л.Х. Государственные цифровые платформы: от концепта к реализации // Вопросы государственного и муниципального управления. 2019. № 4. С. 35.

[19] Мансурова Н.А., Пылина М.С. Стратегии внедрения систем электронного документооборота в организациях // Экономические исследования. 2013. № 3. С. 2.

[20] Россия вошла в первую тройку по темпам роста использования электронных госуслуг - исследование // Ежедневное онлайн-издание D-russia.ru. URL: https:/drussia.ru/rossiya-voshla-v-pervuyu-trojku-po-tempam-rosta-ispolzovaniya-elektronnyhgosuslug-issledovanie.html (дата обращения: 01.01.2020).

[21] Abrahamson E. Managerial Fads and Fashions: The Diffusion and Rejection of Innovations // Academy of Management Review. 1991. Vol. 16(3). P. 586-612.

[22] Паркер Дж. Революция платформ. Как сетевые рынки меняют экономику - и как заставить их работать на вас. М.: Манн, Иванов и Фербер, 2017. С. 99.

[23] OECD Recommendation on Digital Government Strategies. URL: http://www.oecd.org/governance/digital-government/toolkit/12principles/ (accessed: 01.01.2020).

[24]Постановление Правительства РФ от 31.03.2020 № 386-20 «Об утверждении государственной программы Российской Федерации «Информационное общество». URL: $\quad$ https://digital.gov.ru/uploaded/files/postanovlenie-386-20-gp-informatsionnoeobschestvo.pdf (дата обращения: 01.06.2020).

[25]Кабмин продлил госпрограмму «Информационное общество» до 2024 года. URL: https://tass.ru/ekonomika/6307790 (дата обращения: 01.01.2020)

[26]Паспорт государственной программы Российской Федерации «Информационное общество».

http://www.consultant.ru/document/cons_doc_LAW_162184/f09179663f3f8d147faddc7e0a 531e915284e98b/ (дата обращения: 01.01.2020)

[27]Нацпрограмму «Цифровая экономика» интегрируют в госпрограмму «Информационное общество» - проект постановления правительства. URL: https://drussia.ru/natsprogrammu-tsifrovaya-ekonomika-integriruyut-v-gosprogrammu-

informatsionnoe-obshhestvo-proekt-postanovleniya-pravitelstva.html (дата обращения: $01.01 .2020)$

[28]Паспорт федерального проекта «Цифровое государственное управление». UR1: https://digital.gov.ru/uploaded/files/pasport-federalnogo-proekta-tsifrovoe-gosudarstvennoeupravlenie.pdf (дата обращения: 01.01.2020)

[29] Информационное общество в Российской Федерации. 2019: статистический сборник / М. А. Сабельникова, Г. И. Абдрахманова, Л.М. Гохберг, О. Ю. Дудорова и др.; Федеральная служба государственной статистики; Нац. исслед. ун-т «Высшая школа экономики». М.: НИУ ВШЭ, 2019. URL: https://www.gks.ru/storage/mediabank/infoob2019.pdf (дата обращения: 01.01.2020).

[30] CNews: Рейтинг ИКТ-бюджетов регионов $2018 . \quad$ URL: https://www.cnews.ru/reviews/ikt_v_gossektore_2018/review_table/51f0c3a142942b8ba6e4 1e9fe1710c018a3961f6 (дата обращения: 01.01.2020).

[31] 2018: Высшие исполнительные органы государственной власти субъектов РФ. Планы, отчеты, участие. URL: http://system.infometer.org/ru/monitoring/522/rating/ (дата обращения: 01.01.2020).

[32] Сервисы обратной связи с населением в регионах России. URL: https://www.comnews.ru/content/205825/2020-04-27/2020-w18/servisy-obratnoy-svyazinaseleniem-regionakh-rossii (дата обращения: 01.01.2020).

[33]UN $\quad$ E-Government $\quad$ Survey 2020.

https://publicadministration.un.org/egovkb/Portals/egovkb/Documents/un/2020-

Survey/2020\%20UN\%20E-Government\%20Survey\%20(Full\%20Report).pdf обращения: 01.06.2020). 
[34] Worldwide Governance Indicator / The World Bank. URL: http://info.worldbank.org/governance/wgi/ (дата обращения: 01.01.2020).

\title{
Institutional Strategies for the Implementation of Digital Feedback Resources with the Population in the Russian Regions
}

\author{
K. S. Kondratenko
}

\section{St. Petersburg State University}

The article is devoted to the strategies for the implementation of digital channels of public policy in the regions of the Russian Federation. The research problem lies in the uneven implementation of feedback resources in different regions of the Russian Federation, while the implementation of these technologies is described in the passport of the federal project «Digital Public Governance». The main hypothesis of this article is that the regions choose different strategies for introducing public participation channels, solving in different ways the issue of the ratio of monopoly in this area and the possibilities of rational choice when creating regional sites. What implementation strategies lie at the basis of the institutional matrices of the regions of the Russian Federation is the main question of this article.

Keywords: feedback resource, platform, participation, region, region of the Russian Federation, digitalization, institute, institutional strategy, implementation of digital technologies

Reference for citation: Kondratenko K.S. Institutional Strategies for the Implementation of Digital Feedback Resources with the Population in the Russian Regions // The State and Citizens in the Electronic Environment. Vol. 4 (Proceedings of the XXIII International Joint Scientific Conference «Internet and Modern Society», IMS-2020, St. Petersburg, June 17-20, 2020). St. Petersburg: ITMO University, 2020. P. 46-58. DOI: 10.17586/2541-979X-4-46-58

\section{References}

[1] Kondrat'ev N.D. Bol'shie cikly kon'yuktury i teoriya predvideniya. Izbrannye trudy. M.: «Ekonomika», 2002.

[2] Abramovitz M. The passing of the Kuznets cycle. Economica. New series, Vol. 35, No. 140 (Nov., 1968), pp. 349-367.

[3] Juglar C. Des crises commerciales: et de leur retour periodique en France, en Angleterre et aux Etats-Unis / par Clement Juglar; ouvrage couronne par l'Institut (Academie des Sciences morales et politiques). Guillaumin et C-ie, Libraires-Editeurs, 1862.

[4] Kitchin J. Cycles and Trends in Economic Factors // The Review of Economics and Statistics. 1923. Vol. 5, №1. P. 10-16.

[5] Digital government: Building a 21st century platform to better serve the American people, May 23, 2012. URL: https://obamawhitehouse.archives.gov/sites/default/files/omb/egov/digitalgovernment/digital-government-strategy.pdf (accessed: 01.01.2020).

[6] Programma razvitiya Cifrovoj (elektronnoj) ekonomiki v RF do 2035 goda. URL: https://aetp.ru/news/item/410256 (data obrashcheniya: 01.01.2020).

[7] Medennikov V.I. Matematicheskaya model' formirovaniya cifrovyh platform upravleniya ekonomikoj strany // Cifrovaya ekonomika. 2019. № 1 (5). S. 25-35.

[8] Yakovec Yu.V. Global'nye ekonomicheskie transformacii XXI veka. M.: Ekonomika; 2011. S. 46-47.

[9] Polterovich V.M. Institucional'nye lovushki i ekonomicheskie reformy. M., 1998. S. 6.

[10]Veblen T. Teoriya prazdnogo klassa. M.: Izd-vo «Progress», 1984. S. 200-202. 
[11]Atkinson R.D., Ezell S.J. Innovation Economics. The Race for Global Advantage. Yale University Press, 2012. P. 133-161.

[12]Breznitz D. Innovation and the State. Political Choice and Strategies for Growth in Israel, Taiwan, and Ireland. Yale University Press, 2007.

[13]Nort D. Instituty, institucional'nye izmeneniya i funkcionirovanie ekonomiki. M.: Fond ekonomicheskoj knigi "Nachala", 1997. S. 97.

[14]Proekt «Narodnaya ekspertiza». URL: https://narod-expert.ru (data obrashcheniya: 01.01.2020).

[15]Portal «Nash Sankt-Peterburg». URL: https://gorod.gov.spb.ru/ratings/users/ (data obrashcheniya: 01.01.2020).

[16]Polterovich V.M. Strategii institucional'nyh reform. Perspektivnye traektorii // Ekonomika i matematicheskie metody. 2006. T. 42, № 1. S. 3-18.

[17]Williamson O.E. The New Institutional Economics: Taking stock, Looking ahead // Journal of economic literature. 2000. Vol. 38. P. 595-613.

[18]Styrin E.M., Dmitrieva N.E., Sinyatullina L.H. Gosudarstvennye cifrovye platformy: ot koncepta k realizacii // Voprosy gosudarstvennogo i municipal'nogo upravleniya. 2019. № 4. S. 35.

[19]Mansurova N.A., Pylina M.S. Strategii vnedreniya sistem elektronnogo dokumentooborota v organizaciyah // Ekonomicheskie issledovaniya. 2013. № 3. S. 2.

[20]Rossiya voshla v pervuyu trojku po tempam rosta ispol'zovaniya elektronnyh gosuslug issledovanie // Ezhednevnoe onlajn-izdanie D-russia.ru. URL: https://d-russia.ru/rossiyavoshla-v-pervuyu-trojku-po-tempam-rosta-ispolzovaniya-elektronnyh-gosuslugissledovanie.html (data obrashcheniya: 01.01.2020).

[21]Abrahamson E. Managerial Fads and Fashions: The Diffusion and Rejection of Innovations // Academy of Management Review. 1991. Vol. 16(3). P. 586-612.

[22]Parker Dzh. Revolyuciya platform. Kak setevye rynki menyayut ekonomiku - i kak zastavit' ih rabotat' na vas. M.: Mann, Ivanov i Ferber, 2017. S. 99.

[23]OECD Recommendation on Digital Government Strategies. URL: http://www.oecd.org/governance/digital-government/toolkit/12principles/ (data obrashcheniya: 01.01.2020).

[24]Postanovlenie Pravitel'stva RF ot 31.03.2020 № 386-20 «Ob utverzhdenii gosudarstvennoj programmy Rossijskoj Federacii «Informacionnoe obshchestvo». URL: https:/digital.gov.ru/uploaded/files/postanovlenie-386-20-gp-informatsionnoeobschestvo.pdf (data obrashcheniya: 01.06.2020).

[25]Kabmin prodlil gosprogrammu «Informacionnoe obshchestvo» do 2024 goda. URL: https://tass.ru/ekonomika/6307790 (data obrashcheniya: 01.01.2020)

[26]Pasport gosudarstvennoj programmy Rossijskoj Federacii «Informacionnoe obshchestvo». URL: http://www.consultant.ru/document/cons_doc_LAW_162184/f09179663f3f8d147faddc7e0a 531e915284e98b/ (data obrashcheniya: 01.01 .2020 )

[27]Nacprogrammu «Cifrovaya ekonomika» integriruyut v gosprogrammu «Informacionnoe obshchestvo» - proekt postanovleniya pravitel'stva. URL: https://drussia.ru/natsprogrammu-tsifrovaya-ekonomika-integriruyut-v-gosprogrammu-

informatsionnoe-obshhestvo-proekt-postanovleniya-pravitelstva.html (data obrashcheniya: 01.01.2020).

[28]Pasport federal'nogo proekta «Cifrovoe gosudarstvennoe upravlenie». UR1: https:/digital.gov.ru/uploaded/files/pasport-federalnogo-proekta-tsifrovoe-gosudarstvennoeupravlenie.pdf (data obrashcheniya: 01.01.2020)

[29]Informacionnoe obshchestvo v Rossijskoj Federacii. 2019: statisticheskij sbornik / M. A. Sabel'nikova, G. I. Abdrahmanova, L.M. Gohberg, O. YU. Dudorova i dr.; Federal'naya sluzhba gosudarstvennoj statistiki; Nac. issled. un-t «Vysshaya shkola ekonomiki». M.: NIU 
VSHE, 2019. URL: https://www.gks.ru/storage/mediabank/info-ob2019.pdf (data obrashcheniya: 01.01.2020).

[30]CNews: Rejting IKT-byudzhetov regionov $2018 . \quad$ URL: https://www.cnews.ru/reviews/ikt_v_gossektore_2018/review_table/51f0c3a142942b8ba6e4 1e9fe1710c018a3961f6 (data obrashcheniya: 01.01.2020).

[31]2018: Vysshie ispolnitel'nye organy gosudarstvennoj vlasti sub"ektov RF. Plany, otchety, uchastie. URL: http://system.infometer.org/ru/monitoring/522/rating/ (data obrashcheniya: 01.01.2020).

[32] Servisy obratnoj svyazi $\mathrm{s}$ naseleniem $\mathrm{v}$ regionah Rossii. URL: https://www.comnews.ru/content/205825/2020-04-27/2020-w18/servisy-obratnoy-svyazinaseleniem-regionakh-rossii (data obrashcheniya: 01.01.2020).

[33]UN E-Government Survey 2020.

URL: https://publicadministration.un.org/egovkb/Portals/egovkb/Documents/un/2020Survey $/ 2020 \% 20$ UN\%20E-Government\%20Survey\%20(Full\%20Report).pdf obrashcheniya: 01.06.2020).

[34]Worldwide Governance Indicator / The World Bank. URL: http://info.worldbank.org/governance/wgi/ (data obrashcheniya: 01.01.2020). 